\title{
Microbios abordan las naves de Su Majestad
}

\author{
WALTER LEDERMANN D.
}

Microbes aboard Your Magesty's ships

Junto con asumir el trono de Inglaterra, comprendió Isabel Tudor, la primera Dama de Hierro, que para enfrentar la amenaza de la presente y futuras invencibles armadas de España, era indispensable cortar a Felipe II el incesante fluir del oro desde Méjico y Perú. Primero apoyó las andanzas de corsarios como Francis Drake, pero luego se abocó a la creación de una flota regular, encargando la tarea a John Hawkins. Este hábil marino, basándose en las experiencias acumuladas por los corsarios, acostumbrados a luchar contra fuerzas siempre superiores, readecuó los navíos de la época, rebajando la altura de los castillos de proa y de popa, con lo que ganaban en velocidad; aumentando la profundidad de la quilla, para mejorar la estabilidad; y, lo más importante, dotándolos de pesados cañones de largo alcance, aunque por entonces se considerara un arma poco caballerosa. Los galeones españoles quedaron fuera de tiro, al igual que los tanques de Sadam Hussein en la Guerra del Golfo, siglos después.

Isabel Tudor, sintiendo amenazadas sus costas por la Invencible Armada, arengó a sus hombres con palabras inolvidables: Sé que tengo el cuerpo de una débil y flaca mujer, pero tengo el corazón y el hígado de un rey, y de un rey de Inglaterra, por añadidura... El ataque se produjo el 28 de julio de 1588 e Inglaterra lo rechazó con los primeros 34 HMS (His Majesty Ship) pero la verdad es que a la Invencible Armada se la llevó el viento, tanto que algunas medallas conmemorativas decían: Afflavit Deus et dissipantur (Sopló Dios y se disiparon $)^{1}$.

Cuatro siglos después la última Dama de Hierro provocó carcajadas entre los expertos militares cuando decidió armar una flota para proteger las Falkland. Quienes rieron demostraron tan sólo, como diría Cantinflas "su falta de ignorancia", pues basta una somera mirada a la historia para entender que fue ese temple, trasplantado a sus naves, la base del Imperio Británico.

Aunque la sigla ya se había usado antes, desde entonces la floreciente armada inglesa antepuso al nombre de sus navíos las letras H.M.S. Un reciente éxito cinematográfico recreó vivamente la vida en esos navíos, con una disciplina a veces más cruel que rigurosa, que se aplicaba desde los infantiles grumetes a los más curtidos marineros. Pero el aspecto más interesante de esta película radica en el contrapunto entre el capitán, hombre de acción y de guerra, y su cirujano, también hombre de acción, pero de ciencias, enriquecedora relación tomada, sin duda, de la larga convivencia a bordo del H.M.S. Beagle del capitán Fitzroy y Charles Darwin.

Y llegamos al punto de nuestra historia. No sólo en la guerra se lucían los H.M.S., sino también en la investigación científica, y si bien los cirujanos a bordo eran generalmente ignorantes, con cierta frecuencia se embarcaban hombres de ciencia, quienes habían de lidiar contra los elementos, los habitantes de lejanas tierras y también contra unos extraños, pérfidos e invisibles pasajeros, por entonces más adivinados que conocidos, los microbios, capaces de aniquilar con sus desembarcos poblaciones enteras de aborígenes.

Bajo el reinado de Isabel I, llamada Gloriana en la literatura popular de su época, Inglaterra conquistó el mar y extendió su imperio. Richard Hakluyt escribió en 1589, en su obra Las principales navegaciones, tráficos y descubrimientos de la nación inglesa: "al buscar los rincones y partes más opuestos del mundo, al rodear el vasto globo de la tierra más de una vez, ha

Unidad de Segunda Infancia, Hospital Luis Calvo Mackenna.

Recibido: 24 agosto 2005

Aceptado: 31 agosto 2005 
superado a todas las naciones y pueblos del mundo". Pero no pudo superar a la Yersinia pestis, quien llegó a Londres en la primavera de 1665, sino merced al incendio de la misma ciudad un año después. La penuria que acarreó la peste dejó a la flota sin fondos para hacer frente a los holandeses, sus enemigos de entonces, debiendo refugiarse Támesis arriba. Allí, a estos y otros buques, huyeron muchos ciudadanos, creyendo que bastaría poner agua de por medio, pero la peste inexorable igual los alcanzó. La suprema vergüenza llegó en 1667, cuando la flota holandesa forzó la barra de Chatham, quemó cuatro hermosos H.M.S. y se llevó a remolque al orgullo de la armada británica, el H.M.S. Royal Charles, ante la mirada atónita de los impotentes caballeros ingleses. Esta vez el viento no vino en ayuda de los marinos británicos ${ }^{2}$.

Saltemos casi un siglo y abordemos en 1747 el H.M.S. Salisbury, al mando del capitán James Lind, quien está muy preocupado por el escorbuto, enfermedad que diezma las tripulaciones durante los largos viajes, en que pasan meses y meses sin tocar puerto donde reabastecerse de frutas y verduras.

El escorbuto había hecho fracasar expediciones ambiciosas y bien montadas, como la de Lord Anson en 1740, que se proponía conquistar Chile para la corona británica, arrebatándoselo a España, muy venida a menos ya. La expedición comprendía siete navíos de guerra, encabezados por el H.M.S. Centurion y el H.M.S. Gloucester, con 64 y 50 cañones respectivamente, en tanto que la tripulación total de la pequeña armada era superior a dos mil hombres. En el Atlántico las tempestades sólo dejaron los dos buques mencionados, que perdieron contacto entre sí pasado el Estrecho de Magallanes. El escorbuto hizo el resto, y cuando el H.M.S. Centurion tocó tierra en Juan Fernández "era un lazareto flotante, toda la gente de la tripulación estaba tan enferma, que una lancha hubiera sido suficiente para rendirlo"3. Así nos salvamos de ser ingleses, miembros de la Commonwealth... ¿o perdimos la gran oportunidad?

La alimentación a bordo era bastante insana. Para conservar la carne era menester salarla, lo que provocaba la consiguiente sed y el agua a bordo era poca. Cromwell había dispuesto que en los navíos los marineros debían recibir dos libras de vacuno o cerdo o una y media de pescado, pero salada y todo, normalmente devenía podrida mediando el viaje. El otro componente fundamental era la galleta, el biscuit, término derivado del francés bis y cutre, esto es, dos veces cocido; aunque recocida, la galleta se pre- paraba de una manera bien poco higiénica, era durísima y, ya en el proceso de fabricación ponían en ella sus huevos las moscas; antes de comerlas los marinos las golpeaban en la mesa, para que botaran las larvas. Frutas y verduras eran manjares que sólo podían embarcarse de cuando en cuando y el escorbuto reinaba.

En cuanto a la bebida, el mismo Cromwell había dispuesto un galón de cerveza a la semana para cada marinero, pero la cerveza del siglo XVI no se conservaba bien, de modo que se cambió por ron, del cual Inglaterra dispuso en abundancia desde la conquista de Jamaica en 1665. El agua, conservada en barricas, se ponía verde y viscosa al poco tiempo. Se creía que el agua del Támesis se conservaba mejor que otras, y por largos años los H.M.S. embarcaron aguas servidas, llevando la disentería a las lejanas islas de los Mares del Sur, como ya veremos ${ }^{4}$.

Buscando la manera de prevenir y curar el escorbuto, el capitán Lind desarrolló el primer trabajo científico de que haya memoria o, al menos, el primer estudio comparativo. Distribuyó sus enrolados forzosos en 6 grupos de dos enfermos cada uno, los sometió a tratamientos distintos y los observó por seis semanas: El 20 de mayo de 1747, tomé doce pacientes con escorbuto, a bordo del Salisbury en alta mar. Ellos, en general, tenían gomas putrefactos, las manchas y la laxitud, con debilidad en las rodillas Yacían juntos en un lugar y tenían una dieta común...Los resultados de este original y trascendental estudio se muestran en la Tabla 1.

Los resultados de este trabajo, incluidos en el libro que Lind publicó en 1753 - A treatise on the scurvy - con la recomendación de dar a la tripulación una ración diaria de jugo de limón, no con-

Tabla 1. Tratamiento del escorbuto en el HMS Salisbury, 1747

\begin{tabular}{cll}
\hline Número & Terapéutica & Resultado \\
\hline 2 & $\begin{array}{l}\text { 1/4 sidra c/ } 24 \mathrm{~h} \\
25 \text { gotas elixir } \\
\text { vitriolo c/8 h }\end{array}$ & Empeoran \\
& $\begin{array}{l}2 \text { cucharadas vinagre } \\
\text { c/8 h }\end{array}$ & Empeoran \\
2 & $\begin{array}{l}\text { Agua de mar } \\
(\text { ¿solución OMS ?) }\end{array}$ & $\begin{array}{l}\text { Empeoran } \\
2\end{array}$ \\
2 & Electuario del cirujano & Empeoran \\
2 & 2 naranjas y 1 limón / día & 1 cura, \\
& & 1 mejora \\
\hline
\end{tabular}


vencieron a nadie 5 . El libro, dedicado a Lord Anson, el sobreviviente del H.M.S. Centurion, durmió en las estanterías y más de cuarenta años pasaron, con miles de marineros fallecidos, hasta que en 1795 Sir Gilbert Blane convenciera a Lord Spencer, el Primer Lord del Almirantazgo, a disponer el uso obligatorio de este jugo en todos los HMS. Como el hombre es porfiado por naturaleza y siempre parece buscar su propio perjuicio, la práctica cayó en desuso por años en el siglo XIX, hasta que los cinco artículos clásicos de G. Budd en 1842 terminaran por convencer a los más burros 6 .

Una de las expediciones más célebres es la del capitán James Cook, hábil cartógrafo, impulsor de grandes reformas higiénicas y dietéticas en los buques, con las que llamó la atención tanto de la autoridad naval como de la Royal Society. Esta última envió en 1768 un memorial al rey Jorge III, solicitando la confección de un mapa del Pacífico sur y la observación del tránsito de Venus. La elección recayó en James Cook, quien acondicionó para el viaje un buque de 368 toneladas, que rebautizó como H.M.S. Endeavour, zarpando de Cape Horn en agosto de ese año. Llevaba a bordo un botánico, Joseph Banks, y un astrónomo, Charles Green. Cook descubrió Tahití y anexó Australia a la corona británica, entre otras cosas, alcanzando Batavia en octubre de 1770, lugar en que el intercambio cultural con los nativos se completó con un maléfico trueque microbiano: los nativos recibieron la disentería reinante en el H.M.S., probablemente por Shigella dysenteriae, dadas las características del cuadro febril, y devolvieron en cambio algún plasmodio, muriendo de malaria gran parte de la tripulación. Cook realizó en total tres viajes por los mares del sur, utilizando además del H.M.S. Endeavour los navíos acompañantes H.M.S. Resolution, H.M.S. Adventure y H.M.S. Discovery, para terminar asesinado por los nativos en Hawaii en febrero de $1779^{7}$.

Cook trajo numerosos especimenes de sus viajes, encargándose de la interesante pero pesada tarea de catalogarlos uno de los padres de la infectología, nada menos que Edward Jenner. Tan bueno fue el trabajo de éste, que se le ofreció un atractivo contrato para participar en el segundo viaje; el vaccinólogo, a la sazón trabajando con el célebre cirujano John Hunter, no aceptó la oferta y prefirió seguir investigando en tierra firme...

Hemos citado a Cook porque señaló el camino a un trágico navío, cuya penosa historia ha inspirado muchos libros y al menos dos películas: el H.M.S. Bounty. Este era un buque más bien pequeño, especialmente adaptado para su extraña tarea, que consistía en recolectar centenares de almácigos del árbol del pan en Hawaii, y llevarlos para plantarlos en las Indias Orientales, proporcionando así un alimento barato y nutritivo a los esclavos locales... El mando se encomendó al teniente William Bligh, un hombre de 33 años, capacitado y enérgico, que había acompañado a Cook en su segundo viaje y conocía bien esos mares. Tenía otras habilidades y: a la edad de 15 años ya era versado en ciencia y en matemáticas, además de ser un excelente escritor y un fino dibujante. Se inició en el H.M.S. Hunter, un pequeño navío de sólo diez cañones, como ayudante del segundo y tuvo una brillante carrera naval, mereciendo ser recordado más allá de la historia del motín ${ }^{8}$.

El H.M.S. Bounty salió de Inglaterra el 23 de diciembre de 1787 y estaba en plena tarea, cargando arbolitos, cuando estalló el famoso motín de Fletcher Christian, el 28 de abril de 1789. Pero no nos apresuremos y vayamos por partes, analizando las desgracias una por una.

A poco andar vino la primera pérdida. El ahora capitán Bligh anota: el jueves 9 tuvimos la desgracia de perder a uno de nuestros marineros, James Valentine. Había sido este pobre hombre uno de los más robustos y sanos a bordo, hasta nuestra llegada a la Adventure Bay, donde se quejó de cierta indisposición ligera. Se le hizo una sangría y quedó mejor. Poco después de haberlo sangrado, el brazo se le inflamó y le dolía; la inflamación aumentó y le sobrevino una tos cavernosa y una extraña dificultad para respirar, hasta que murió.

A la luz de los conocimientos actuales, está claro que Valentine fue asesinado entre el médico, quien lo sangró e infectó, y su cómplice desconocido, una bacteria. El cirujano Thomas Huggan era incompetente y beodo y de él se queja Bligh de continuo: El tal cirujano llevaba largo tiempo enfermo, a consecuencia de sus excesos e indolencia. Últimamente apenas si salía de su camarote... Este desdichado bebía tanto y era tan enemigo del ejercicio, que jamás se consiguió en todo el viaje hacerle dar una docena de vueltas por la cubierta... Se le desembarcó y enterró por la tarde y nombré para sustituirle al señor Thomas Denman Ledward.

Este segundo no era médico y podemos, a lo sumo, compararlo con un hábil auxiliar de una posta de urgencia: atendía heridos, entablillaba fracturas, amputaba como mejor podía y revisaba a los marineros periódicamente en busca de enfermedades venéreas. Poco después de ascendido a cirujano tuvo que atender al jefe Teppahu, 
aquejado de tos y ronquera; Ledward le encontró dos orificios cicatrizados en el paladar, que parecían haber sido de gran tamaño; no se complicó con diagnóstico ni tratamiento y dictaminó cáncer fatal ${ }^{9}$.

¿Cuál fue la bacteria cómplice, capaz de desencadenar rápidamente septicemia y compromiso pulmonar al marinero Valentine? La actuación de un Vibrio vulnificus es tentadora. En las cálidas agua de Tahití, donde retozaron todos los marineros, la presencia de esta bacteria es más que probable, y tanto el paciente como el médico pudieron tenerla en las manos, además que el agua de mar mojaba a diario a la tripulación. Conocidas son también la rapidez de acción del vibrión marino, su tendencia a provocar celulitis y su capacidad invasora en las septicemias ${ }^{10}$. Al término de las azotainas arrojaban un balde de agua marina sobre las espaldas laceradas, no está claro si por una supuesta acción higiénica, desinfectante o cicatrizante, o si por simple crueldad, para que doliese más. Cuando el buque estaba anclado en aguas cálidas, perfectamente una multitud de vibriones pudo haber proliferado en esos baldes, y tanto el vibrión mencionado como otras especies relacionadas se han encontrado en los últimos cuarenta años en las aguas del Pacífico, desde Australia hasta Hawaii.

El capitán Bligh era pródigo en azotes; en el juicio a los amotinados declaró que los había ordenado pocas veces, y así aparece en su diario, pero los testigos probaron otra cosa, como se expresa en la tabla II, si bien la mayoría de los oficiales de la época encontró los castigos normales y proporcionados a las faltas ${ }^{11}$ (Tabla 2).

Aunque los tahitianos eran de costumbres muy liberales y sus mujeres amorosas y complacientes, Bligh los estimaba casi inmunes a las consecuencias, afirmando: salimos de Tahiti con sólo dos enfermos de venéreo, lo que demuestra que tales enfermedades no se han extendido allí. Los indígenas les conceden poquísima importancia y vimos numerosos casos de gentes infestadas que, después de una ausencia de quince a veinte días, reaparecían sin el menor signo visible de enfermedad. No sé cual es su método de tratamiento, pero creo que tiene que ayudar mucho su sistema de vida y su dieta. Veíamos, no obstante, muchísima gente con estigmas escrofulosos y llagas, que ellos negaban que tuviese origen venéreo, opinión en que les acompañaba nuestro cirujano. Es probable que tuviesen sífilis: al cabo de veinte días volvían sin el chancro, para maravilla del ignorante Bligh y del improvisado cirujano, pero por doquiera estaban las lúes terciarias a su vista $^{9}$..

El capitán tenía buenas nociones de higiene. Hizo preparar unas barricas especiales para mantener el pan seco y al abrigo de los roedores; obligaba a su gente a hacer ejercicios, y a lavar y secar su ropa con frecuencia. El entrepuente se limpiaba a diario y, si el tiempo no permitía ventilar abriendo las escotillas, hacía fumigaciones, fregando los pisos con agua hirviente para matar las cucarachas. Producido el motín, fue embarcado en un pequeño bote con quince subordinados fieles y casi sin víveres; y, en una hazaña náutica impresionante, recorrió en tan frágil embarcación cuatro mil millas marinas hasta Batavia, con pérdidas mínimas. Estando en el bote, hacía que la mitad de la tripulación se pusiera de pie por turnos, para ejercitarse; cuando llovía, todos se quitaban las ropas, las metían al mar y las retorcían, de manera que parecían secas, y volvían a vestirlas; en los momentos de mayor penuria les repartía dos cucharaditas de ron por cabeza. Así, sostiene el capitán, se mantuvieron saludables.

Bligh, que había comenzado su aprendizaje naval embarcándose a los nueve años de edad, tuvo una exitosa carrera después del motín del H.M.S. Bounty, comandando un buen número de viajes científicos, lo que le permitió entrar a la famosa Royal Society como miembro de número. Tuvo, sin embargo, que soportar un nuevo

Tabla 2. Azotes ordenados por Bligh en el viaje del H.M.S. Bounty

\begin{tabular}{llr}
\hline Marinero & Causal & No $^{\text {Azotes }}$ \\
\hline Mathew Quintal & Insolencia con Primer oficial & 24 \\
Cabo John Williams & Negligencia al izar la sonda & 6 \\
Alexander Smith & Permitir robo de "hembra" de timón & 12 \\
Charles Churchill & Deserción & 24 \\
William Muspratt & Deserción & 48 \\
John Millward & Deserción & 48 \\
Isaac Martín & Por pegarle a un indio & 19 \\
\hline
\end{tabular}




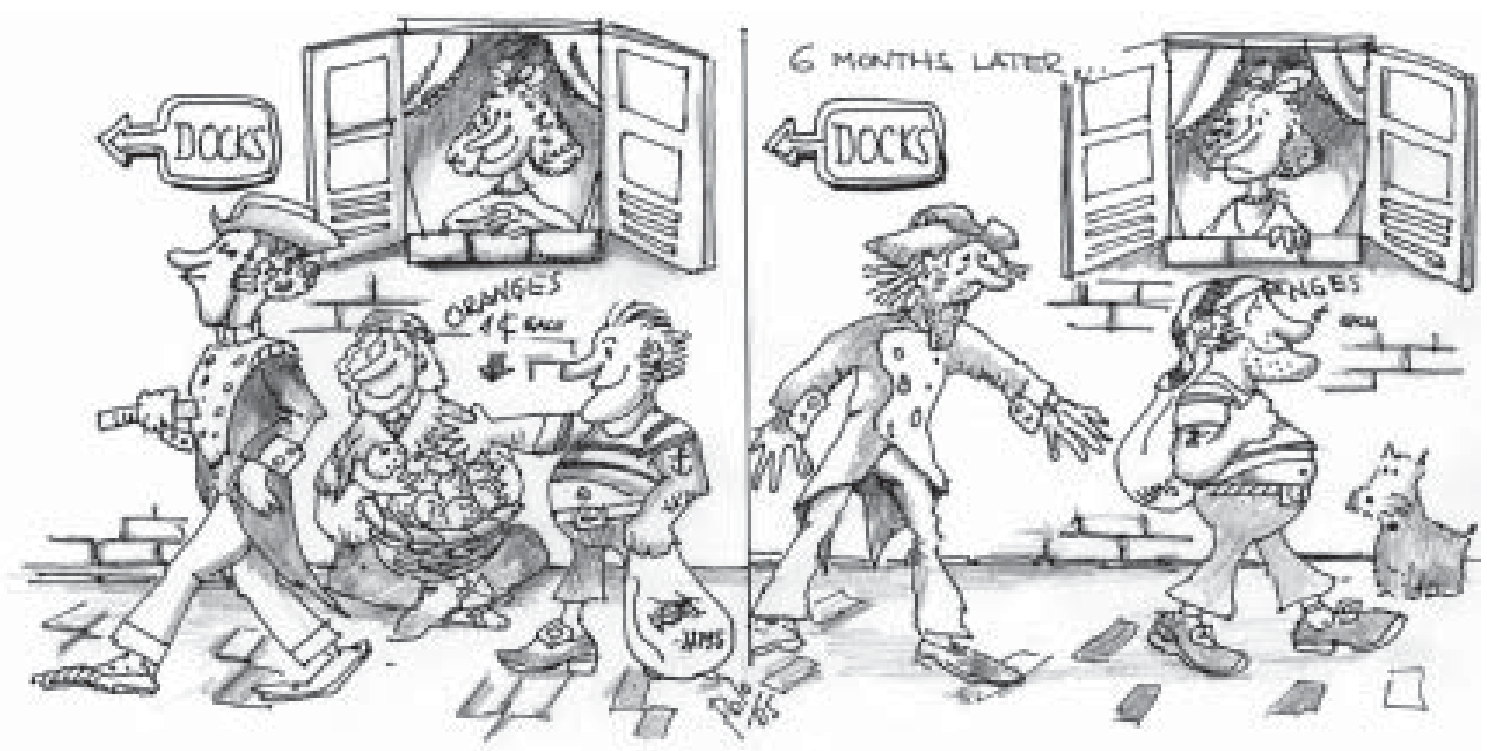

motín en 1797, más sangriento y violento que el anterior, cuando varias naves se sublevaron contra el Vicealmirante Buckner: él se mantuvo firme en su buque y no se amotinó. Por último, como Gobernador de Nueva Gales del Sur (hoy Australia) sufrió un tercer motín en 1808: los colonos lo mandaron de vuelta a Inglaterra, poniendo fin a su carrera naval ${ }^{12}$.

Sin duda el más importante de los viajes científicos de la armada británica es el que hiciera Charles Darwin en el H.M.S. Beagle. La historia es sobradamente conocida y extensa, pero de poco interés infectológico. Fue el segundo viaje del capitán Fitzroy a cargo del H.M.S. Beagle, que duraría cinco años, desde 1831 a 1836. El buque no era muy grande -97 pies de largo- y cargaba una tripulación de 74 personas, incluyendo al capitán, tres oficiales, un doctor, un artista, la tripulación y... Darwin, quien lo llenó tanto de especimenes, que en la cámara que compartía con dos oficiales no tenía cómo extender los pies durante la noche. Se supone que la flora y fauna de las Islas Galápagos le inspiraron la teoría de la evolución de las especies, pero para nosotros resulta más atrayente su paso por Chile y el traslado a Inglaterra de tres fueguinos, uno de los cuales murió de la viruela que lo esperaba en la civilización ${ }^{13}$. El único dato infectológico lo encontramos en una secuela de los viajes del H.M.S. Beagle.

La peregrina idea de Fitzroy y Darwin, quienes llegaron a ser muy amigos y luego se disgustaron por la teoría evolucionaria, era civilizar a los nativos en Inglaterra, educarlos y llevarlos de vuelta a Tierra del Fuego, para que ellos a su vez educaran a su gente. El más famoso de estos pioneros, Jemmy Button, fue encontrado veinte años después en condiciones deplorables, de nuevo salvaje e implicado en el atroz asesinato de unos misioneros y de la tripulación del navío particular Allen Gardiner en Wulaia, Navarino. Sólo sobrevivió el cocinero de 23 años, Alfred Coles, quien desde el barco presenció la matanza. Al ver que los botes nativos se acercaban, perdió la cabeza, olvidó que el barco tenía cañones, y trató de huir en otro bote.

Atrapado, fue objeto de la curiosidad de los nativos, quienes decidieron afeitarlo, arrancándole las cejas y la barba con conchas de mejillones; al pobre las cruentas heridas se le infectaron y se llenó de furúnculos, que las indias trataban de curarle con emplastos de hierbas. Lo triste de la historia es que, rescatado por los ingleses, tampoco el cirujano de turno pudo sanarlo con sus ungüentos, y el estafilococo se enseñoreó del cocinero por mucho tiempo ${ }^{14}$.

Conocemos la carrera triunfal de Darwin luego de su viaje. Fitzroy tenía su vena científica y por ello congeniaron. El capitán fue pionero en el campo del pronóstico del tiempo y llegó a ser jefe del Departamento Metereológico Británico, desarrollando un sistema de vigilancia de tormentas, prototipo del actual pronóstico diario; incluso inventó un barómetro barato y útil. En 1865, presa de profunda depresión, se degolló con su navaja de afeitar el 30 de abril. Darwin inició una 
suscripción para costear sus deudas y probablemente ayudó a pagar sus funerales ${ }^{15}$.

Terminamos esta reseña con la historia netamente infectológica del H.M.S. Sainte Jeanne D'Arc, bello navío de guerra de 64 cañones, integrante de la armada inglesa en el Mediterráneo, en el que enfermaron 86 marineros entre junio y octubre de 1860 , proponiendo el cirujano a bordo el traslado de toda la tripulación transitoriamente a otro navío, sin duda con la enérgica oposición de su estoico capitán, para así abortar el brote. La opinión médica se impuso y la tripulación emigró al H.M.S. Victory, con lo cual cesaron las neumonías; sin embargo, al retornar al H.M.S.Sainte Jeanne D'Arc se reiniciaron los $\operatorname{casos}^{16}$. Desconocemos el final de la historia. ¿Se convirtió, acaso, el HMS Sainte Jeanne D'Arc en un buque maldito y fue exorcizado por la Iglesia...? ¿O, simplemente, el neumococo desembarcó en las costas griegas y el navío regresó al Atlántico en busca de vientos más recios, que aventaran "las miasmas"?

Allá van, entre la espesa bruma, doblando el Cabo, los gallardos navíos de su Majestad, y el viento trae el eco de las voces de mando...Tooodo a babooor...

Y el neumococo los acompaña.

\section{Referencias}

1.- Churchill W. Historia de Inglaterra y de los pueblos de habla inglesa. Ediciones Peuser, Buenos Aires 1958; II: $105-14$.

2.- Defoe D. El año de la peste. Seix Barral, Barcelona 1969.

3.- Reccius A. Esculapio en el Reino de Chile. Zig-Zag, Santiago 1967; XII: 125-33.
4.- Ritchie CIA. La alimentación en el mar. En: La búsqueda de las especias. Alianza Editorial, S.A., Madrid 1984; pp 31-50.

5.- Hampton J. Evidence-based medicine, opinion-based medicine, and real-world medicine. Persp in Biol Med 2002; 45 (4): 549-68.

6.- Sharman I. Vitamins: essential dietary constituents discovered. Endeavour New Series 1977; I (3/4): $97-$ 102.

7.- Taylor NM. Cook, James. Collier's Encyclopedie. Crowell Collier and MacMillan, Inc.,USA 1967; 7: 287-8.

8.- The real Captain Bligh. http: //www.chanel4.com/ history/microsites/R/real-lives

9.- Bligh W. Viaje al mar del sur emprendido por orden de S.M. con el fin de transportar árboles del Pan a las Antillas en el bajel de S.M. la Bounty. Londres 1792. En: Mackaness G. Verdadera historia de la rebelión en la Bounty. Editorial Juventud S.A., Barcelona 1963; pp: $17-178$.

10.- Johnston J M, Becker S F, McFarland D P H. Vibrio vulnificus. Man and the sea. JAMA 1985; 253 (19): 2850-3.

11.- Notas de las sesiones del Consejo de Guerra celebrado en Portsmouth el 12 de agosto de 1792, contra diez individuos acusados de sublevación a bordo del bajel de S.M. la Bounty. Con un apéndice en que se relatan las verdaderas causas y circunstancias de tan desdichado asunto; las más importantes de las cuales se han sustraído, hasta ahora, a conocimiento del público. Londres J. Deighton, 1794. En: Mackaness G. Verdadera historia de la rebelión en la Bounty. Editorial Juventud S.A., Barcelona 1963; pp: 179-253.

12.- Sires R V, Bligh W. Collier's Encyclopedie. Crowell Collier and MacMillan, Inc., USA 1967; 4: 254.

13.- Darwin C. Autobiografía. Alianza Editorial S.A. Madrid 1993.

14.- Marks R L. Tres hombres a bordo del Beagle. Segunda parte: El verdadero intermedio. Javier Vergara Editor S.A. Bs. Aires 1994; pp: 81-142.

15.- Marks R L. Tres hombres a bordo del Beagle. Cuarta parte: El verdadero fin y el fin de dos de los hombres. Javier Vergara Editor S.A. Bs. Aires 1994; pp: 161-98.

16.- Eulenburg, A. Pulmón. Diccionario Enciclopédico de Medicina y Cirugía Prácticas. Jubera, Hermanos, Editores, Madrid 1890; XI: 4. 